Интернет-журнал «Отходы и ресурсы» / Russian journal of resources, conservation and recycling https://resources.today 2017, Том 4, №3 / 2017, Vol 4, No 3 https://resources.today/issues/vol4-no3.html

URL статьи: https://resources.today/PDF/03RRO317.pdf

DOI: 10.15862/03RRO317 (http://dx.doi.org/10.15862/03RRO317)

Ссылка для цитирования этой статьи:

Пинаев В.Е. Экология человека. Арт-терапия — ресурсы здоровья // Отходы и ресурсы, 2017 №3, https://resources.today/PDF/03RRO317.pdf (доступ свободный). Загл. с экрана. Яз. рус., англ. DOI: 10.15862/03RRO317

For citation:

Pinaev V.E. (2017). Human ecology. Art-therapy — health resources. Russian journal of resources, conservation and recycling, [online] 3(4). Available at: https://resources.today/PDF/03RRO317.pdf (in Russian). DOI: 10.15862/03RRO317

\title{
УДК 330.15
}

\section{Пинаев Владимир Евгеньевич}

Российский университет дружбы народов, Россия, Москва ${ }^{1}$ Доцент кафедры «Прикладной экологии» Кандидат экономических наук E-mail: pinaev-ve@mail.ru

\section{Экология человека. Арт-терапия - ресурсы здоровья}

Аннотация. Статья посвящена проблеме реабилитации больных после инсульта и оказанию помощи лежачим больным с застойными явлениями в легких. Предложено применение музыкальных инструментов для разработки двигательных функций рук - калимба и гусли; применение макетов оружия и боеприпасов для восстановления подвижности рук у проходивших воинскую службу. Для восстановления работы легких (ликвидации застольных явлений) предложено применение мелодик, блок-флейт и губных гармошек. Мероприятия по реабилитации предложено проводить силами родственников, при недостаточном количестве медицинского персонала, что может послужить не только скорейшей реабилитации, но и улучшению отношений внутри семьи в том числе укреплению связи между поколениями при проведении реабилитационных мероприятий родителям силами детей.

Ключевые слова: инсульт; застойные явления в легких; реабилитация; помощь родственников; восстановление функций; экология человека; семья; родственные связи; музыкальные инструменты; макеты оружия и боеприпасов лежачие больные; амуниция

Традиционно к методам реабилитации относится манипуляция бытовыми предметами ключами, телефоном, столовыми приборами. Могут быть предложены дополнительные варианты реабилитации посредством манипуляции.

Следует отметить, что вопросы реабилитации больных после инсульта и других заболеваний, связанных с необходимостью восстановления двигательной функции $[1,5]$, зачастую возлагаются на родственников. Лежачие больные также могут быть подвержены заболеванием, связанным с застоем в легких [4]. $[2,3]$.

Чаще всего эти проблемы решаются преимущественно медикаментозными методами

${ }^{1}$ 117198, Москва, ул. Миклухо-Маклая, д. 6 
На практике родственники всегда желают помочь врачам делать их работу, но не знают, как, и во многих случаях такая помощь сводится только к благодарности.

Рассмотрим несколько направлений реабилитации больных силами родственников. Конечно, для тех учреждений, где есть врач-реабилитолог, такой необходимости может быть и нет. С другой стороны, надо помнить, что количество врачей в любом медицинском учреждении ограничено, как и время которое они могут посвятить каждому пациенту [6]. Таким образом, некоторая информация для родственников, заинтересованных в скорейшей реабилитации больного может быть полезна.

Отметим, что покупка инвентаря для реабилитации сопряжена с затратами, но возможность ускоренной реабилитации вполне их может компенсировать. Можно также предположить, что не все выздоровевшие больные заберут свой инвентарь домой за ненадобностью и в медицинских учреждениях может образоваться комплект инвентаря.

\section{Разработка рук/восстановление подвижности пальцев после инсульта}

Ниже на фотографиях 1-7 представлены некоторые инструменты и оборудование, которое может быть использовано для восстановления подвижности пальцев рук и в дальнейшем и рук целиком.

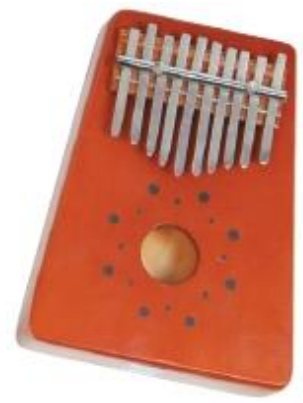

\section{Рисунок 1. Калимба (источник: http://dynatone.ru)}

Калимба удобна тем, что ее можно положить под руку больному; звук не раздражающий. Отзывается звуком на малейшее прикосновение к язычкам.

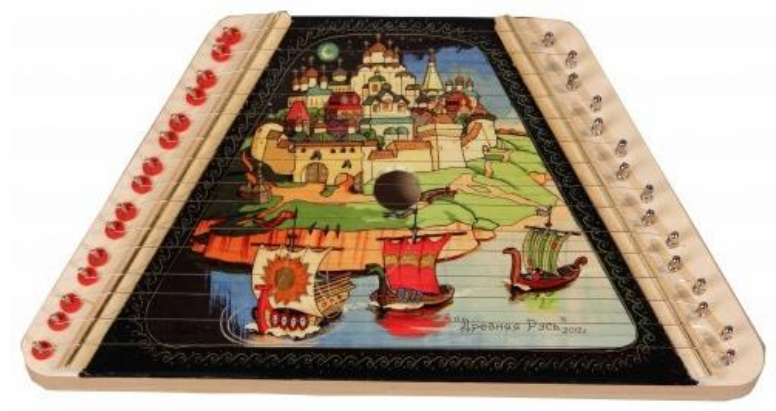

Рисунок 2. Гусли (источник: http://dynatone.ru)

Гусли удобны для лежачего больного с одной парализованной рукой. Звук у гуслей не громкий и мелодичный - соседей по палате сильно не потревожит. В данном комплекте идет схема игры, подкладываемая под струны, так что можно играть довольно осмысленно и стройно. 


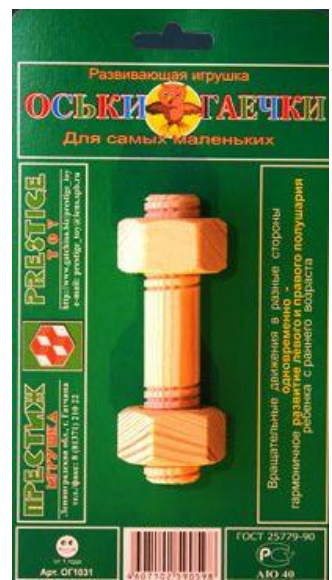

Рисунок 3. Болты-винты из дерева (источник: http://www.rodnye-igrushki.ru)

Предпочтение деревянным изделиям отдано в связи с тем, что они более приятны на ощупь и более легкие, чем металлические и не холодят руку.

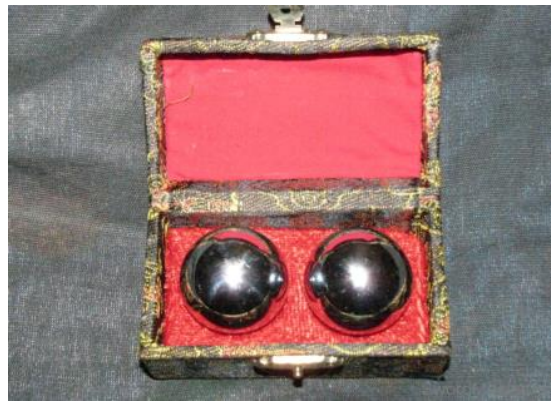

Рисунок 4. «Китайские шарики» (источник: http://swordmaster.ru)

Шарики можно положить на кровать под парализованную руку и предложить больному их двигать по кругу. В дальнейшем шарики можно крутить - перемещать на ладони.

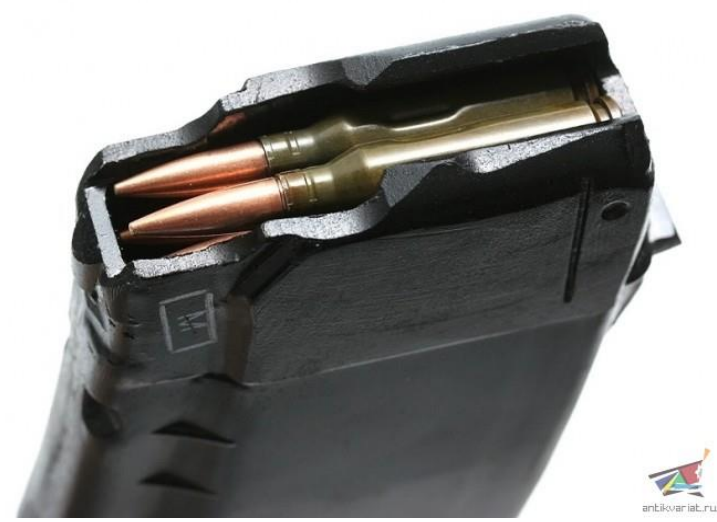

Рисунок 5. Магазин с муляжсами патронов (источник: https://antikvariat.ru)

Данный вариант особенно может быть интересен при реабилитации военных, в том числе пенсионеров и мужчин, служивших в армии. Заряжая магазин можно разработать не только руки, но и затронуть зоны мозга, отвечающие за воспоминания молодости. Для людей старшего поколения - воспоминания возраста 18-20 лет, когда проходили службу в Советской армии.

Наиболее универсальным вариантом может считаться магазин к автомату Калашникова (AК) с учебными патронами. Возможно использование магазина для пистолетов ПМ и ТТ, но это более специфично - для офицеров и ветеранов. 


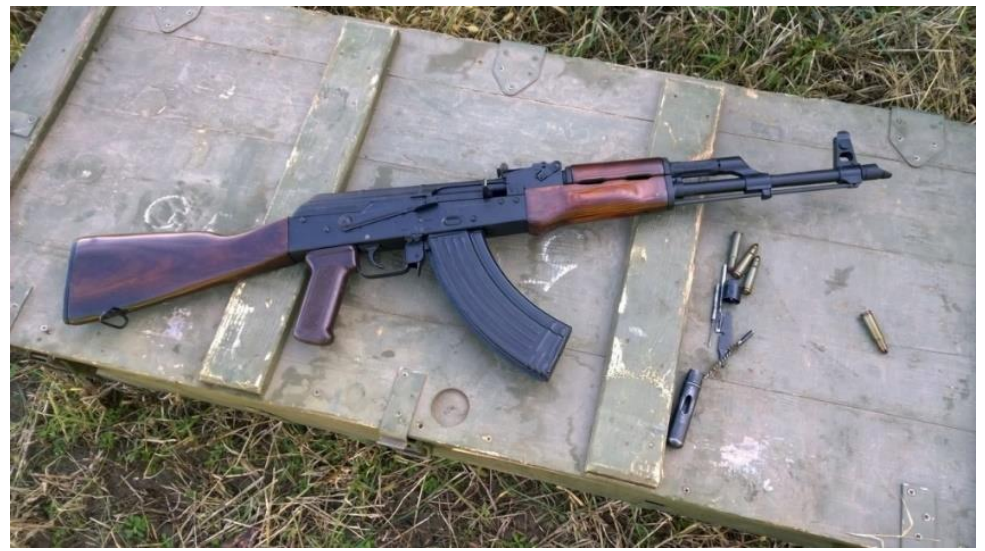

Рисунок 6. Охолощенный муляж автомата Калашникова (источник: https://kupit-shp.ru)

Данная полноразмерная копия позволяет собирать и разбирать автомат. Функции данного приспособления такие же как и у магазина к автомату - пробудить у человека воспоминания молодости и автоматизм в действиях. Естественно, прежде чем приносить такое устройство реабилитации в больницу лучше согласовать с лечащим и главным врачом, чтоб не оказаться с самыми благими намерениями в ближайшем отделении полиции для выяснения обстоятельств вместо реабилитации родственника.

\section{Усиление воздухообмена в легких}

Для лежачих больных актуальной проблемой могут стать застойные явления в легких. Помимо медикаментозной терапии может быть предложено использование музыкальных инструментов, представленных на фотографиях 8-10.

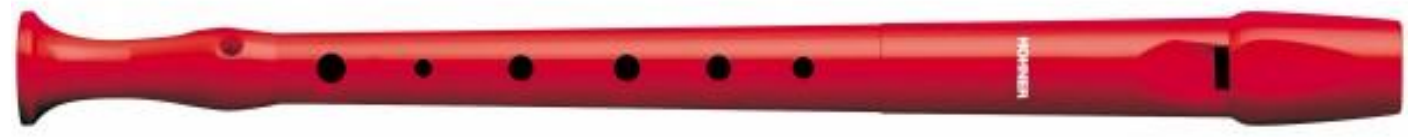

Рисунок 7. Блокфлейта (источник: http://dynatone.ru)

Пластиковый корпус удобен для дезинфекции, малый вес.

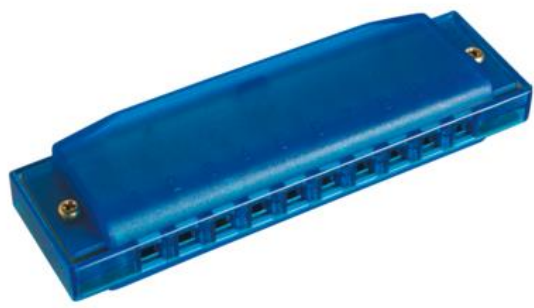

Рисунок 8. Губная гармошка (источник: http://dynatone.ru)

Благодаря тому, что инструмент изготовлен из пластика - легко держать и дезинфицировать 


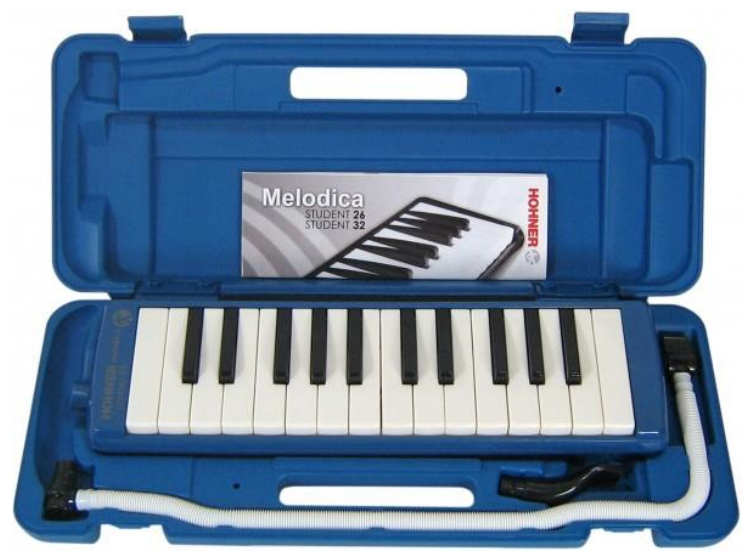

Рисунок 9. Мелодика духовая (источник: http://dynatone.ru)

Эта модель очень удобна для лежачих больных - благодаря гибкой трубке можно играть в горизонтальном положении. Наиболее удачный вариант для реабилитации в комплексе - звук извлекается только при совмещении двух действий - дутье в трубку и нажатие клавиш.

Естественно необходимо договориться с соседями по палате и этажу о такой музыкальной реабилитации, а также с персоналом лечебного заведения. В отличие от предложенных выше калимбы и гуслей, звук у духовых инструментов может быть довольно громким и мелодичность хаотично извлекаемых звуков сомнительна.

\section{Цена вопроса}

Ниже в таблице 1 представлены примеры цен на средства реабилитации.

Таблица 1

Стоимостные характеристики предлагаемых средств реабилитации

\begin{tabular}{|l|c|l|}
\hline \multicolumn{1}{|c|}{ Средство реабилитации } & $\begin{array}{c}\text { Цена, } \\
\text { руб. }\end{array}$ & \multicolumn{1}{c|}{ Источник информации } \\
\hline Губная гармошка & 450 & http://dynatone.ru/info9101015 \\
\hline Блокфлейта & 1250 & http://dynatone.ru/info999013125 \\
\hline Металлические шары & 200 & $\begin{array}{l}\text { http://swordmaster.ru/product/kitajskie-metallicheskie- } \\
\text { shary/ }\end{array}$ \\
\hline $\begin{array}{l}\text { Магазин к автомату Калашникова и } \\
\text { муляжи патронов соответствующег } \\
\text { калибра 30 шт. }\end{array}$ & 2500 & $\begin{array}{l}\text { http://oldthing.ru/1308-uchebnye-patrony-dlya-ak-762-h- } \\
\text { Оал.html }\end{array}$ \\
\hline Охолощенный автомат Калашникова & 27500 & $\begin{array}{l}\text { http://kupit-shp.ru/shp/element/okholoshchennyy- } \\
\text { avtomat-kalashnikova-akm-skhp-s-avtoognem.html }\end{array}$ \\
\hline Деревянный болт с двумя винтами & 240 & http://www.rodnye-igrushki.ru \\
\hline Гусли & 5000 & http://dynatone.ru/info999013636 \\
\hline Калимба & 1800 & $\underline{\text { http://dynatone.ru/info999010885 }}$ \\
\hline
\end{tabular}

Примечание: данный набор не является единственно приемлемым и разным пациентам могут быть показаны разные/другие модели (источник: составлено автором)

Следует отметить, что существует практика размещения пациентов со сходными заболеваниями в одной палате. Это дает возможность не покупать каждому весь набор средств реабилитации, а наладить взаимодействие между больными и их родственниками. Но при групповом использовании средств реабилитации важным вопросом является дезинфекция и хранение средств реабилитации. 
Основной принцип в подборе средств - использование того что интересно и/или знакомо человеку, проходящему реабилитацию. Для кого-то может оказаться интересным, например, рисование пальчиковыми красками - но тут не обойтись без помощи: хотя бы держать лист, краски, вытирать пальцы. Важно начать реабилитацию как можно раньше [7], чтобы человек не разуверился в своих силах, потеряв навыки, и не разочаровался в своем существовании.

\section{ЛИТЕРАТУРА}

1. Ермакова Н.Г. Особенности личности больных с последствиями инсульта в условиях стационарной реабилитации // Известия Российского государственного педагогического университета им. А.И. Герцена № 68. 2008. С. 32-42.

2. Кадыков А.С., Шахпаронова Н.В. Ранняя реабилитация больных, перенесших инсульт. Роль медикаментозной терапии // Нервные болезни № 1 / 2014. С. 22-25.

3. Бабак С.В. Цитиколин в реабилитации постинсультных пациентов // Архивъ внутренней медицины № 5. 2013. С. 48-51.

4. Тетенев Ф.Ф., Бодрова Т.Н., Макаров В.М. Биомеханика дыхания при кардиогенном застое в легких // Сибирский медицинский журнал (Иркутск) № 1. том 6. 1996. С. 57-59.

5. Костенко Е.В., Петрова Л.В., Лебедева А.В., Бойко А.Н. Комплексная реабилитация пациентов с постинсультной спастичностью руки в амбулаторнополиклинических условиях // Нервные болезни 3. 2013. С. 30-38.

6. Соломченко М.А., Головкин Д.И. Применение средств лечебной физической культуры для реабилитации больных с инсультом // Ученые записки Орловского государственного университета. Серия: Гуманитарные и социальные науки № 4 (48) 2012. C. 388-395.

7. Перевощиков П.В., Шестаков В.В. Эффективность реабилитации больных инсультом в ранний восстановительный период // Пермский медицинский журнал № 2. том 27. 2010. С. 10-14. 
Pinaev Vladimir Evgen'evich

People's friendship university of Russia (RUDN University), Russia, Moscow E-mail: pinaev-ve@mail.ru

\title{
Human ecology. Art-therapy - health resources
}

\begin{abstract}
The article is dedicated to the problem of rehabilitation of ill people after insult and assistance to bed patients with pulmonary engorgement. Musical instruments are proposed for hands motor function recovery - gusli and kalimba; weapons mock-ups and mock-up of ammunition for hands motor function recovery for patients with military past. For recovery of lungs work (liquidation of pulmonary engorgement) use of melodics, block-flutes and mouthorgans. Rehabilitation measures are proposed to be held with assistance of relatives, when amount of medical personnel is not sufficient, what cal lead not only to fastest rehabilitation, but also to improvement of relations inside the family, including intergeneration's links, when rehabilitation of parents is held by children.
\end{abstract}

Keywords: insult (cerebral crisis); pulmonary engorgement; rehabilitation; assistance of relatives; recovery of functions; human ecology; family; links to relatives; musical instruments; mockup of weapons and ammunition; bed patients; ammunition

\section{REFERENCES}

1. Ermakova N.G. (2008). Features of the personality of patients with the consequences of stroke in the conditions of inpatient rehabilitation. Izvestiya of the Russian State Pedagogical University. A.I., 68, pp. 32-42 (in Russia).

2. Kadykov A.S., Shakhparonova N.V. (2014). Early rehabilitation of patients who had a stroke. Role of drug therapy. Nervous diseases, 1, pp. 22-25 (in Russia).

3. Babak S.V. (2013). Citicoline in the rehabilitation of post-stroke patients. Archive of internal medicine, 5, pp. 48-51 (in Russia).

4. Tetenev F.F., Bodrova T.N., Makarov V.M. (1996). Biomechanics of respiration with cardiogenic stasis in the lungs. Siberian Medical Journal, 1, pp. 57-59 (in Russia).

5. Kostenko E.V., Petrova L.V., Lebedeva A.V., Boiko A.N. (2013). Complex rehabilitation of patients with post-stroke spasticity of the hand in out-patient-polyclinic conditions. Nervous diseases, 3, pp. 30-38 (in Russia).

6. Solomchenko M.A., Golovkin D.I. (2012). The use of means of therapeutic physical culture for the rehabilitation of patients with stroke. Scientific notes of Orel State University, 4(48), pp. 388-395 (in Russia).

7. Perevoshchikov P.V., Shestakov V.V. (2010). Effectiveness of rehabilitation of stroke patients in the early recovery period. Perm Medical Journal, 2(27), pp. 10-14 (in Russia). 